\section{Regioselective 2'-Silylation of Purine Ribonucleosides for Phosphoramidite RNA Synthesis}

This unit describes high-yield procedures for protection of purine ribonucleosides based on a reaction that allows highly regioselective 2 -silylation. The $H$-phosphonate monoester group produced in the silylation reaction is then cleaved, without silyl migration (Song et al., 1999; Zhang et al., 1997), to give intermediates ready for phosphitylation to yield the phosphoramidites. This method gives overall yields that are three times the best yields available by conventional procedures for adenosine (see Basic Protocol 1) and guanosine (see Basic Protocol 2), but offers no advantage for cytidine or uridine.

\section{SYNTHESIS OF 5'-O-(4,4'-DIMETHOXYTRITYL)-2'-O-tert- BUTYLDIMETHYLSILYL-6- $N$-ACYLADENOSINE}

This protocol makes use of transient protection of the $2^{\prime}, 3^{\prime}$-diol moiety of a ribonucleoside (S.2 in Fig. 2.8.1) by reaction with $N, N$-dimethylformamide dimethylacetal (Zemlicka, 1963) to prevent the small, but potentially troublesome, tritylation of the $2^{\prime}$-hydroxyl that otherwise accompanies tritylation of the $5^{\prime}$-hydroxyl (Zhang et al., 1997). The 2',3'-Odimethylaminomethylene group is cleaved by any protic solvent. The $N$-dimethylaminomethylene group is cleaved by treatment with either aqueous ammonia or methylamine. The phenoxyacetylation reaction is carried out using the hydroxybenzotriazole active ester of phenoxyacetic acid after transient hydroxyl protection with trimethylchlorosilane.

The regioselective silylation of the $\mathrm{N}$ - and $5^{\prime}$-O-protected adenosine and guanosine derivatives (S.4 and S.13, respectively) presumably occurs by a reaction sequence in which the phenyl- $H$-phosphonate reacts first with tert-butyldimethylchlorosilane to generate the corresponding diester, which then undergoes a transesterification with $\mathbf{S . 4 / S . 1 3}$ to generate a mixture of isomers (S.5/S.14). Subsequent transfer of the tert-butyldimethylsilyl (TBDMS) group predominantly to the more acidic 2 '-hydroxyl gives $\mathbf{S . 6 a} / \mathbf{S 1 5 a}$ along with $10 \%$ to $15 \%$ of the $3^{\prime}-O$-TBDMS isomers.

The $H$-phosphonate moiety is removed by reaction of the isomers of S.6a,b/S15a,b with ethylene glycol or glycerol. The extraordinarily facile transesterification of $H$-phosphonate diesters in the presence of a vicinal hydroxyl group effects the conversion to S.8a,b/S.17a,b quantitatively within minutes, presumably via the intermediate S.7a,b/S.16a,b.

After careful purification, $\mathbf{S 8 a} / \mathbf{S . 1 7} \mathbf{a}$ are converted to the phosphoramidites $\mathbf{S . 9 / S . 1 8}$ by reaction with 2-cyanoethyl tetraisopropylphosphorodiamidite using diisopropylammonium tetrazolide as a catalyst. A short silica gel column removes the excess reagent.

For $H$-phosphonate synthesis, monomers like S.6a/S.15a but without amino protection can be prepared by a similar route (Zhang et al., 1997). The labile phenoxyacetyl group used here does not survive the polar conditions required for purification of the charged $H$-phosphonates.

\section{Materials}

Adenosine

Pyridine (reagent grade or better)

Dimethylformamide dimethyl acetal

Nitrogen source
UNIT 2.8

BASIC PROTOCOL 1

Protection of Nucleosides for Oligonucleotide Synthesis

\subsection{1}

Supplement 6 


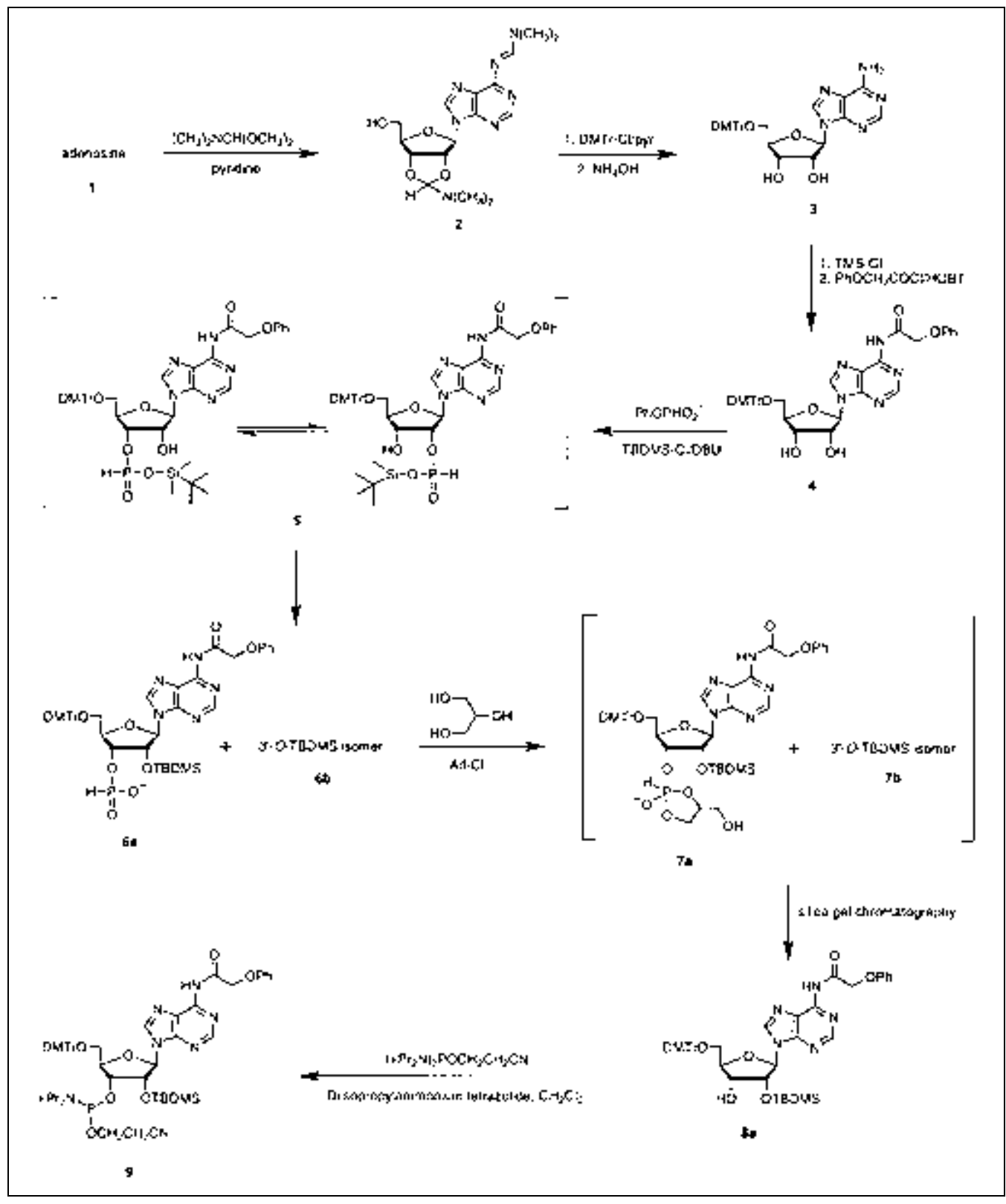

Figure 2.8.1 Dimethoxytritylation $N$-phenoxyacetylation, silylation, dephosphonylation, and phosphitylation of adenosine. Abbreviations: Ad, adamantanecarbonyl; DBU, 1,8-diazabyclyclo[5.4.0]undex-7-ene; DMTr, 4,4'-dimethoxytrityl; HOBT, 1-hydroxybenzotriazole; $\mathrm{Ph}$, phenyl; $i$ - $\mathrm{Pr}$, isopropyl; TMS, trimethylsilyl; TBDMS, tert-butyldimethylsilyl. Regioselective
2'-Silylation of Purine Ribonucleosides for Phosphoramidite RNA Synthesis

Acetonitrile (anhydrous, dried over $3 \AA$ molecular sieves)

$0.1 \mathrm{M}$ triethylammonium acetate (TEAA)

4,4'-Dimethoxytrityl chloride (DMTr-Cl)

$5 \%(\mathrm{v} / \mathrm{v})$ methanol in dichloromethane

Dichloromethane

Concentrated aqueous ammonium hydroxide

$N$-Methylmorpholine

Trimethylchlorosilane

Adenosine phenoxyacetylating reagent (see recipe)

Sodium bicarbonate

Ethyl acetate 
Petroleum ether

Ammonium phenyl- $H$-phosphonate (see recipe)

1,8-Diazabicyclo[5.4.0]undec-7-ene (DBU)

tert-Butyldimethylsilyl chloride (TBDMS.Cl)

$0.5 \mathrm{M}$ potassium phosphate buffer, $\mathrm{pH} 7.0$ (APPENDIX 2A)

Glycerol

1-Adamantanecarbonyl chloride

Diisopropylammonium tetrazolide

Argon source

2-Cyanoethyl tetraisopropylphosphorodiamidite

Methylene chloride (anhydrous)

Triethylamine (anhydrous)

250-mL and 25-mL round-bottom flask

Rotary evaporator

Silica gel 60F TLC plates (Merck)

Waters XTerra $2.5-\mu \mathrm{m} \mathrm{C18}$ chromatography column

Vacuum pump

Septum

Vent needle

Desiccator with $\mathrm{P}_{2} \mathrm{O}_{5}$

Additional reagents and equipment for TLC (APPENDIX 3D), column chromatography (APPENDIX 3E), and HPLC (UNIT 10.5)

\section{Tritylate adenosine}

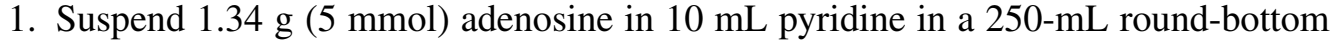
flask with a magnetic stir bar and concentrate to dryness using a rotary evaporator and vacuum pump. Repeat this azeotropic drying process two times with 10-mL portions of pyridine.

2. Suspend the dry adenosine in $60 \mathrm{~mL}$ pyridine, reduce the volume to $\sim 50 \mathrm{~mL}$, and add $2.6 \mathrm{~mL}$ ( $20 \mathrm{mmol})$ dimethylformamide dimethyl acetal.

3. Seal the flask with a septum and displace the air with nitrogen through a vent needle in the septum. After a few minutes, remove the nitrogen line and vent needle. Allow to sit for $1 \mathrm{hr}$.

4. Concentrate to an oil, dissolve the oil in $60 \mathrm{~mL}$ pyridine, and concentrate to $\sim 50 \mathrm{~mL}$.

5. Add $2.03 \mathrm{~g}$ (6 mmol) 4,4'-dimethoxytrityl chloride and stir 2 to $3 \mathrm{hr}$.

6. Check the reaction by HPLC using a gradient of 2:98 to 80:20 acetonitrile: $0.1 \mathrm{M}$ TEAA, pH 6.8 on a C18 column or by TLC (APPENDIX 3D) on silica gel plates using 60F methanol in dichloromethane (Table 2.8.1). Examine the plate under UV light, and then hold it over an open container of fresh aqueous $\mathrm{HCl}$ to observe trityl-containing spots.

When the TLC plate is held over an open container of $\mathrm{HCl}$, the fumes will cause any trityl-containing spots to turn a bright orange.

If the reaction is not complete after $1 \mathrm{hr}$, add 0.5 mmol more of $4,4^{\prime}$-dimethoxytrityl chloride and wait an additional $1 \mathrm{hr}$.

HPLC and TLC mobility of compounds in the reaction are listed in Table 2.8.1.

Protection of 
Table 2.8.1 HPLC and TLC Mobility of Compounds Described in Figures 2.8.1 and 2.8.2

\begin{tabular}{|c|c|c|c|}
\hline \multicolumn{4}{|l|}{ Adenosine } \\
\hline \multirow[b]{2}{*}{$\begin{array}{l}\text { Compound } \\
\text { (structure number in figures) }\end{array}$} & \multicolumn{2}{|c|}{ TLC $R_{\mathrm{f}}$ (methanol:dichloromethane) } & \multirow[b]{2}{*}{$\begin{array}{l}\text { HPLC }^{a} \\
\text { Retention time, min }\end{array}$} \\
\hline & $(5: 95)$ & $(10: 90)$ & \\
\hline 3 & 0.09 & 0.27 & 11.3 \\
\hline 4 & 0.08 & 0.37 & 12.5 \\
\hline $6 a, 6 b$ & $\begin{array}{l}0.01 \text { minor } \\
0.03 \text { major }\end{array}$ & $\begin{array}{l}0.08 \text { minor } \\
0.13 \text { major }\end{array}$ & $\begin{array}{l}12.7 \text { major } \\
13.4 \text { minor }\end{array}$ \\
\hline $8 a$ & 0.55 & 0.83 & 15.7 \\
\hline $8 b$ & 0.48 & 0.75 & 16.2 \\
\hline 9 & $0.80,0.84$ & $0.73,0.90$ & $-b$ \\
\hline \multicolumn{4}{|l|}{ Guanosine } \\
\hline 11 & 0.00 & 0.10 & - \\
\hline 13 & 0.05 & 0.44 & 11.0 \\
\hline $15 \mathrm{a}, \mathrm{b}$ & - & - & $\begin{array}{l}11.1 \text { major } \\
12.2 \text { minor }\end{array}$ \\
\hline $17 \mathrm{a}$ & 0.41 & 0.58 & 13.9 \\
\hline $17 b$ & 0.32 & 0.53 & 14.5 \\
\hline 18 & $0.38,0.43$ & $0.58,0.83$ & $-^{b}$ \\
\hline
\end{tabular}

7. Add $10 \mathrm{~mL}$ methanol to quench the excess reagent, wait $5 \mathrm{~min}$, and then pour the solution into $100 \mathrm{~mL}$ water containing $1 \mathrm{~g}(12 \mathrm{mmol})$ sodium bicarbonate.

8. Extract the solution two times with $80-\mathrm{mL}$ portions of dichloromethane, concentrate the combined organic layers, dissolve the residue in $25 \mathrm{~mL}$ pyridine, and add $25 \mathrm{~mL}$ concentrated aqueous ammonium hydroxide. Seal the flask tightly and heat $5 \mathrm{hr}$ at $60^{\circ} \mathrm{C}$.

Use caution in heating this closed system. Use a shield and carefully inspect the flask for cracks or defects that might weaken it.

9. Cool to room temperature, open the flask carefully, and check the mixture by HPLC or TLC to have a record of the retention time or $R_{\mathrm{f}}$ value of $\mathbf{S . 3}$ (Table 2.8.1).

10. Concentrate the mixture with frequent additions of pyridine so that the water is removed azeotropically to give $\mathbf{S . 3}$ as an oil. Dry by evaporation of pyridine as in step 1, leaving dry $\mathbf{S . 3}$ in $\sim 50 \mathrm{~mL}$ pyridine.

\section{Phenoxyacetylate}

11. To the solution of $\mathbf{S . 3}$ in $50 \mathrm{~mL}$ dry pyridine, add $5.5 \mathrm{~mL}$ (50 mmol) $N$-methylmorpholine. Seal the flask with a septum and displace the air with nitrogen through a vent needle in the septum. Keep the nitrogen flowing slowly.

12. Cool this mixture in an ice-bath and add $3.2 \mathrm{~mL}(25 \mathrm{mmol})$ trimethylchlorosilane over 3 to $5 \mathrm{~min}$.

Trimethylchlorosilane is highly moisture sensitive. Use of special bottles such as the Aldrich SURE-SEAL system will help to prevent deterioration of the reagent.

13. Remove the flask from the ice-bath and maintain for $1 \mathrm{hr}$ at room temperature. 
14. Add all of the freshly prepared adenosine phenoxyacetylating reagent using a syringe. Remove the nitrogen line and vent needle and stir 12 to $18 \mathrm{hr}$.

15. Check the reaction by HPLC or TLC.

If the reaction is not complete, add 0.5 mmol more of the phenoxyacetylating reagent and wait an additional $2 \mathrm{hr}$.

16. Pour the mixture into $100 \mathrm{~mL}$ water containing $2.5 \mathrm{~g} \mathrm{(30} \mathrm{mmol)} \mathrm{sodium} \mathrm{bicarbonate,}$ extract two times with $100-\mathrm{mL}$ portions of dichloromethane, and concentrate the combined organic layers to dryness.

17. Dissolve the residue in $50 \mathrm{~mL}$ pyridine, add $25 \mathrm{~mL}$ water, and stir 12 to $18 \mathrm{hr}$.

18. Concentrate the solution and check the mixture by HPLC or TLC.

19. Purify the residue by column chromatography (APPENDIX $3 E$ ) on silica gel using 0:100 to $15: 85(\mathrm{v} / \mathrm{v})$ methanol/dichloromethane to give pure $\mathbf{S . 4}$ in yields of up to $\sim 90 \%$.

\section{Silylate}

20. To $2.63 \mathrm{~g}$ ( $15 \mathrm{mmol})$ of ammonium phenyl- $H$-phosphonate, add $2.3 \mathrm{~mL}$ ( $15 \mathrm{mmol})$ DBU and co-evaporate with $50 \mathrm{~mL}$ pyridine.

21. Dissolve the residue in $120 \mathrm{~mL}$ pyridine, concentrate to $\sim 100 \mathrm{~mL}$, add $2.26 \mathrm{~g} \mathrm{(15}$ mmol) TBDMS-Cl and mix. Place $3.52 \mathrm{~g}(5 \mathrm{mmol}) \mathrm{S.4}$ in a dry $250-\mathrm{mL}$ round-bottom flask and dry by evaporation of pyridine as in step 1. Using a syringe, add the mixture prepared in step 21 to $\mathbf{S . 4}$, followed by $3.8 \mathrm{~mL}$ (25 mmol) DBU.

The silylation reaction can be performed using other $N$ - and 5'-O-protected adenosine derivatives.

22. Stir 5 to $8 \mathrm{hr}$ and check the reaction by HPLC or TLC.

If the reaction is not complete, add 1 mmol more of DBU and wait another $2 \mathrm{hr}$.

23. Pour the mixture into $100 \mathrm{~mL}$ of $0.5 \mathrm{M}$ aqueous potassium phosphate buffer, $\mathrm{pH} 7.0$, and extract two times with $100-\mathrm{mL}$ portions of dichloromethane. Concentrate the combined organic layers to dryness.

\section{Dephosphonylate}

24. Add $1.38 \mathrm{~g}(15 \mathrm{mmol})$ glycerol to the residue and dry the mixture by co-evaporation with $50 \mathrm{~mL}$ pyridine.

25. Dissolve the residue in $60 \mathrm{~mL}$ pyridine, concentrate to $\sim 50 \mathrm{~mL}$, and add $2.98 \mathrm{~g}(15$ mmol) of 1-adamantanecarbonyl chloride. Stir $10 \mathrm{~min}$.

26. Pour the solution into $100 \mathrm{~mL}$ of $0.5 \mathrm{M}$ aqueous potassium phosphate buffer and extract two times with 100-mL portions of dichloromethane. Concentrate the combined organic layers to dryness.

27. Check the mixture by HPLC or TLC and purify the residue by column chromatography in silica gel using 60:40 to 100:0 (v/v) ethyl acetate petroleum ether to give S.8a in yields of $\sim 65 \%$ from S.4.

The isomers can be distinguished because the 2'-O-silyl isomer runs faster than the 3'-O-silyl isomer both on silica gel and C18 reversed-phase chromatography. See Table 2.8.2 for NMR data. If desired, the identity can be verified by two-dimensional COSY NMR: for the 2'-O-silyl isomer, the hydroxyl resonance only shows a cross-peak to the 3'-H resonance, while for the 3'-O-silyl isomer, the hydroxy resonance only shows a cross-peak to the 2 '-H resonance. 


\section{Phosphitylate}

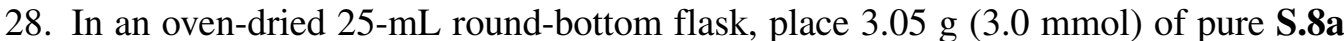
and $0.28 \mathrm{~g}(1.5 \mathrm{mmol})$ of diisopropylammonium tetrazolide. Dry the flask and a rubber septum (not inserted) in an evacuated desiccator over $\mathrm{P}_{2} \mathrm{O}_{5}$ overnight.

It is critical that the reaction be absolutely anhydrous. Further, the starting material must be pure, since the product can only tolerate a very fast chromatographic purification to remove the excess reagent.

29. Open the desiccator under argon and immediately insert the septum. Displace any air with argon through a vent needle in the septum. Add $15 \mathrm{~mL}$ of dry dichloromethane through the septum and swirl 5 to $10 \mathrm{~min}$ to dissolve the solids completely.

30. Cool the flask in an ice bath at $0^{\circ}$ and add $1.00 \mathrm{~mL}(3.0 \mathrm{mmol})$ of 2-cyanoethyl tetraisopropylphosphorodiamidite. Keep the mixture at $0^{\circ}$ for one hour and swirl it every 15 min or so.

31. Remove a small sample carefully with a syringe with an oven-dried needle to check by HPLC or TLC. Normally, the reaction will be about $75 \%$ to $85 \%$ done.

32. Remove the flask from the ice bath and keep it at room temperature. Add another 0.5 $\mathrm{mL}(1.5 \mathrm{mmol})$ of the phosphitylating reagent and allow the reaction to proceed for several more hours. Check by HPLC or TLC no more than once per hr, each time using a dry syringe needle.

Note that the product exists as a pair of diastereomers, since the phosphorus atom is chiral. Any inadvertent hydrolysis of the product results in a pair of hydrogen phosphonate diesters that are much more polar than the product. Some hydrolysis will occur during HPLC and TLC analysis.

33. Prepare a small glass column containing about $10 \mathrm{~cm}$ of silica gel packed in $98: 2$ dry methylene chloride:triethylamine.

34. Place the reaction mixture directly onto this column and load it using nitrogen pressure. Wash the column using nitrogen pressure with about $30 \mathrm{~mL}$ of $98: 2$ dry methylene chloride:triethylamine, followed by 49:1:50 dry methylene chloride:triethylamine:dry acetonitrile.

The product normally elutes after 20 to $50 \mathrm{~mL}$, sometimes just after a yellow impurity.

It is very important to work as quickly as possible so as not to leave the product in solution any longer than necessary, since it will start to degrade immediately. A quick way to check the fractions for product is to spot them on a grid marked on a TLC plate. The plate does not have to be developed, just checked for UV-active material. Then the first and last fractions can be checked by HPLC or on a developed TLC plate.

36. Combine the fractions containing pure product and evaporate to a foam. Dry the product in a desiccator over $\mathrm{P}_{2} \mathrm{O}_{5}$.

37. Check the product for purity by ${ }^{31} \mathrm{P}$ NMR (Table 2.8.2).

BASIC PROTOCOL 2

Regioselective 2'-Silylation of Purine Ribonucleosides for Phosphoramidite RNA Synthesis

\section{SYNTHESIS OF 5'-O-(4,4'-DIMETHOXYTRITYL)-2'-O-tert-} BUTYLDIMETHYSILYL-2- $N$-ACYLGUANOSINE

In this protocol, $\mathrm{N}$ - and $5^{\prime}-O$-protected guanosine (S.13 in Fig. 2.8.2) is generated in a similar fashion as S.4 in Basic Protocol 1, except that guanosine is first amino protected (whereas adenosine is first tritylated) because the $N$-phenoxyacetyl derivative is crystalline and therefore easier to isolate. Silylation, dephosphorylation, and phosphitylation are performed following the procedures for adenosine. 


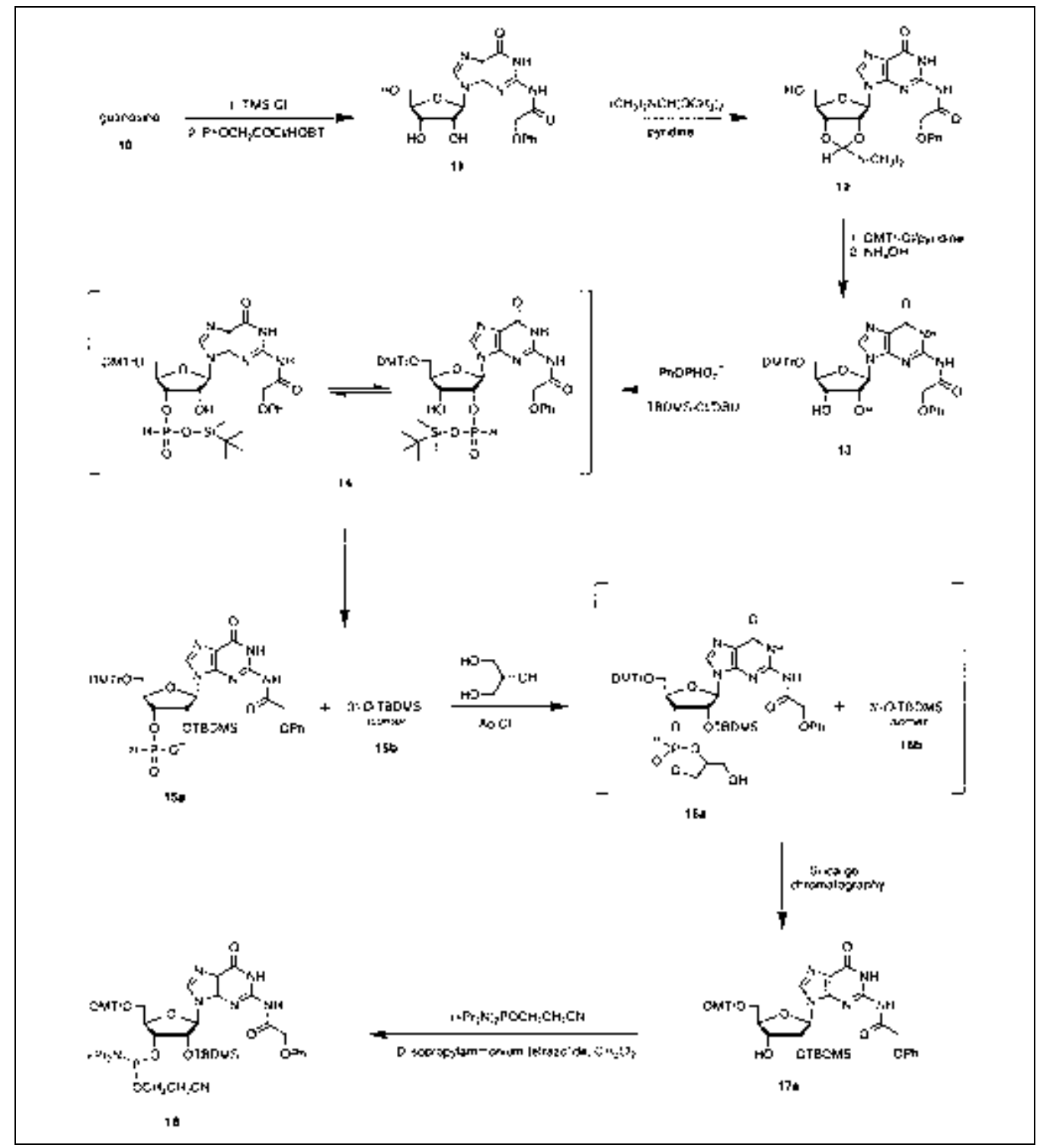

Figure 2.8.2 N-Phenoxylacetylation, dimethoxytritylation, silylation, dephosphonylation, and phosphitylation of guanosine. Abbreviations: Ad, adamantanecarbonyl; DBU, 1,8-diazabyclyclo[5.4.0]undec-7-ene; DMTr, 4,4'-dimethoxytrityl; HOBT, 1-hydroxybenzotriazole; Ph, phenyl; i-Pr, isopropyl; TMS, trimethylsilyl; TBDMS, tert-butyldimethylsilyl.

\section{Materials}

Guanosine

Pyridine

Nitrogen source

Trimethylchlorosilane

Guanosine phenoxyacetylating reagent (see recipe)

2-Propanol

Methanol

Dichloromethane

Acetonitrile (anhydrous, dried over $3 \AA$ molecular sieves)

$0.1 \mathrm{M}$ triethylammonium acetate (TEAA)

Dimethylformamide dimethyl acetal

4,4'-Dimethoxytrityl chloride (DMTr-Cl)

Methanol

Protection of

Nucleosides for

Oligonucleotide

Synthesis 
Sodium bicarbonate

Dichloromethane

Ammonium phenyl- $H$-phosphonate (see recipe)

1,8-Diazabicyclo[5.4.0] undec-7-ene (DBU)

tert-Butyldimethylsilyl chloride (TBDMS-Cl)

$0.5 \mathrm{M}$ potassium phosphate buffer, $\mathrm{pH} 7.0$ (APPENDIX 2A)

Glycerol

1-Adamantanecarbonyl chloride

5:95 to $15: 85(\mathrm{v} / \mathrm{v})$ acetone/dichloromethane (optional; for phosphoramidite synthesis)

250-mL round-bottom flasks

Magnetic stir bar

Rotary evaporator

Silica gel 60F TLC plates (Merck)

Waters XTerra 2.5- $\mu \mathrm{m} \mathrm{C18}$ chromatography column

Vacuum pump

Septum

Vent needle

Desiccator with $\mathrm{P}_{2} \mathrm{O}_{5}$

Additional reagents and equipment for TLC (APPENDIX $3 D$ ) and column chromatography (APPENDIX 3E)

\section{Phenoxyacetylate guanosine}

1. Suspend $1.42 \mathrm{~g}(5 \mathrm{mmol})$ guanosine in $10 \mathrm{~mL}$ pyridine in a $250-\mathrm{mL}$ round-bottom flask with a magnetic stir bar and concentrate to dryness using a rotary evaporator and vacuum pump. Repeat this azeotropic drying process two times with $10-\mathrm{mL}$ portions of pyridine.

2. Suspend the dry guanosine in $60 \mathrm{~mL}$ pyridine and concentrate to $\sim 50 \mathrm{~mL}$.

3. Seal the flask with a septum and displace the air with nitrogen through a vent needle in the septum. Keep the nitrogen flowing slowly.

4. Cool this mixture in an ice-bath and add $3.8 \mathrm{~mL}(30 \mathrm{mmol})$ trimethylchlorosilane over 3 to $5 \mathrm{~min}$.

Trimethylchlorosilane is highly moisture sensitive. Use of special bottles such as the Aldrich SURE-SEAL system will help to prevent deterioration of the reagent.

5. Remove the flask from the ice bath and maintain $1 \mathrm{hr}$ at room temperature.

6. Add all the freshly prepared guanosine phenoxyacetylating reagent using a syringe. Remove the nitrogen line and vent needle and stir $36 \mathrm{hr}$.

7. Add $30 \mathrm{~mL}$ water, concentrate the solution, and co-evaporate two times with $30-\mathrm{mL}$ portions of water to a final volume of $\sim 15 \mathrm{~mL}$.

8. Filter the slurry.

The solid contains both the product (S.11) and some 1-hydroxybenzotriazole from the guanosine phenoxyacetylating reagent.

Regioselective 2'-Silylation of Purine Ribonucleosides for Phosphoramidite RNA Synthesis

9. To remove the 1-hydroxybenzotriazole, shake the solid thoroughly with a 50-mL portion of water and filter. Repeat with $20 \mathrm{~mL}$ water followed by three $20-\mathrm{mL}$ portions of 2-propanol to give $\mathbf{S . 1 1}$ as a colorless solid in yields of up to $95 \%$. 
10. Check the product by HPLC using a gradient of 2:98 to 80:20 acetonitrile: $0.1 \mathrm{M}$ TEAA pH 6.8 on a C18 column or TLC (APPENDIX 3D) on silica gel 60F plates using the appropriate concentration of methanol in dichloromethane (Table 2.8.1).

11. Dry the product in a desiccator over $\mathrm{P}_{2} \mathrm{O}_{5}$ at least overnight and check that the yield is $<100 \%$.

A yield $>100 \%$ means that the product is contaminated with hydroxybenzotriazole and one should repeat the thorough shaking with 2-propanol.

\section{Tritylate}

12. Dissolve the dry $\mathbf{S . 1 1}$ in $60 \mathrm{~mL}$ pyridine, concentrate to $\sim 50 \mathrm{~mL}$, and add $0.8 \mathrm{~mL}$ (6 mmol) dimethylformamide dimethyl acetal.

13. Seal the flask with a septum and displace the air with nitrogen through a vent needle in the septum. After a few minutes, remove the nitrogen line and vent needle. Allow to sit for $1 \mathrm{hr}$.

The dimethylformamide dimethyl acetal will slowly replace the phenoxyacetyl group so the time and the amount of this reagent used is kept to a minimum.

14. Concentrate to an oil, dissolve the oil in $60 \mathrm{~mL}$ pyridine, and concentrate to $\sim 50 \mathrm{~mL}$.

15. Add $2.03 \mathrm{~g}$ (6 mmol) 4,4'-dimethoxytrityl chloride and stir 2 to $3 \mathrm{hr}$.

16. Check the reaction by HPLC or TLC. Examine the plate under UV light, and then hold it over an open container of fresh aqueous $\mathrm{HCl}$ to observe trityl-containing spots.

When the TLC plate is held over an open container of $\mathrm{HCl}$, the fumes will cause any trityl-containing spots to turn a bright orange.

If the reaction is not complete after $1 \mathrm{hr}$, add an additional $0.5 \mathrm{mmol}$ of 4,4'-dimethoxytrityl chloride and wait another $1 \mathrm{hr}$.

17. Add $10 \mathrm{~mL}$ methanol to quench the excess reagent, wait $5 \mathrm{~min}$, and then pour the solution into $100 \mathrm{~mL}$ water containing $1 \mathrm{~g}(12 \mathrm{mmol})$ sodium bicarbonate.

18. Extract the solution two times with $80-\mathrm{mL}$ portions of dichloromethane and concentrate the combined organic layers to dryness.

19. Check the mixture by HPLC or TLC. Purify the residue by column chromatography (APPENDIX 3E) on silica gel using 0:100 to 10:90 (v/v) methanol/dichloromethane to give pure $\mathbf{S . 1 3}$ in yields of up to $\sim 90 \%$.

\section{Silylate}

20. To $2.63 \mathrm{~g}$ ( $15 \mathrm{mmol})$ ammonium phenyl- $H$-phosphonate, add $2.3 \mathrm{~mL}(15 \mathrm{mmol}) \mathrm{DBU}$ and co-evaporate with $50 \mathrm{~mL}$ pyridine.

21. Dissolve the residue in $120 \mathrm{~mL}$ pyridine, concentrate to $\sim 100 \mathrm{~mL}$, add $2.26 \mathrm{~g}$ (15 mmol) TBDMS-Cl and mix. Place $3.52 \mathrm{~g} \mathrm{(5} \mathrm{mmol)} \mathrm{S.4} \mathrm{in} \mathrm{a} \mathrm{dry} 250-\mathrm{mL}$ round-bottom flask and dry by evaporation of pyridine as in step 1. Using a syringe, add the mixture prepared in step 21 to $\mathbf{S . 4}$, followed by $3.8 \mathrm{~mL}(25 \mathrm{mmol}) \mathrm{DBU}$.

The silylation reaction can be performed using other $N$ - and $5^{\prime}$-O-protected guanosine derivatives.

22. Stir 5 to $8 \mathrm{hr}$ and check the reaction by HPLC or TLC.

If the reaction is not complete, add 1 mmol more of DBU and wait another $2 \mathrm{hr}$.

Protection of Nucleosides for Oligonucleotide Synthesis

2.8.9

Supplement 6 
23. Pour the mixture into $100 \mathrm{~mL}$ of $0.5 \mathrm{M}$ aqueous potassium phosphate buffer, $\mathrm{pH} 7.0$, and extract two times with $100-\mathrm{mL}$ portions of dichloromethane. Concentrate the combined organic layers to dryness.

\section{Dephosphonylate}

24. Add $1.38 \mathrm{~g}(15 \mathrm{mmol})$ glycerol to the residue and dry the mixture by co-evaporation with $50 \mathrm{~mL}$ pyridine.

25. Dissolve the residue in $60 \mathrm{~mL}$ pyridine, concentrate to about $\sim 50 \mathrm{~mL}$, and add 2.98 $\mathrm{g}(15 \mathrm{mmol})$ of 1-adamantanecarbonyl chloride. Stir $10 \mathrm{~min}$.

26. Pour the solution into $100 \mathrm{~mL}$ of $0.5 \mathrm{M}$ potassium phosphate buffer, $\mathrm{pH} 7.0$, and extract two times with 100-mL portions of dichloromethane. Concentrate the combined organic layers to dryness.

27. Check the mixture by HPLC or TLC and purify the residue by column chromatography on silica gel using 5:95 to 15:85 acetone/dichloromethane to give S.17a in yields of $\sim 65 \%$ from $\mathbf{S . 1 3}$.

The isomers can be distinguished because the 2'-O-silyl isomer runs faster than the $3^{\prime}$-O-silyl isomer both on silica gel and C18 reversed-phase chromatography. See Table 2.8.2 for NMR data. If desired, the identity can be verified by two-dimensional COSY NMR: for the 2'-O-silyl isomer, the hydroxyl resonance only shows a cross-peak to the 3'-H resonance, while for the 3'-O-silyl isomer, the hydroxyl resonance only shows a cross-peak to the $2^{\prime}$-H resonance.

\section{Phosphitylate}

28. In an oven-dried $25-\mathrm{mL}$ round-bottom flask, place $3.05 \mathrm{~g}(3.0 \mathrm{mmol})$ of pure $\mathbf{S . 1 7 a}$ and $0.28 \mathrm{~g}(1.5 \mathrm{mmol})$ of diisopropylammonium tetrazolide. Dry the flask and a rubber septum (not inserted) in an evacuated desiccator over $\mathrm{P}_{2} \mathrm{O}_{5}$ overnight.

It is critical that the reaction be absolutely anhydrous. Further, the starting material must be pure, since the product can only tolerate a very fast chromatographic purification to remove the excess reagent.

29. Open the desiccator under argon and immediately insert the septum. Displace any air with argon through a vent needle in the septum. Add $15 \mathrm{~mL}$ of dry dichloromethane through the septum and swirl 5 to 10 min to dissolve the solids completely.

30. Cool the flask in an ice bath at $0^{\circ}$ and add $1.00 \mathrm{~mL}(3.0 \mathrm{mmol})$ of 2-cyanoethyl tetraisopropylphosphorodiamidite. Keep the mixture at $0^{\circ}$ for $1 \mathrm{hr}$ and swirl it every 15 min or so.

31. Remove a small sample carefully with a syringe with an oven-dried needle to check by HPLC or TLC. Normally, the reaction will be about $75 \%$ to $85 \%$ done.

32. Remove the flask from the ice bath and keep it at room temperature. Add another 0.5 $\mathrm{mL}(1.5 \mathrm{mmol})$ of the phosphitylating reagent and allow the reaction to proceed for several more hours. Check by HPLC or TLC no more than once per hr, each time using a dry syringe needle.

Note that the product exists as a pair of diastereomers, since the phosphorus atom is chiral. Any inadvertent hydrolysis of the product results in a pair of hydrogen phosphonate diesters that are much more polar than the product. Some hydrolysis will occur during HPLC and TLC analysis.

Regioselective 2'-Silylation of Purine Ribonucleosides for Phosphoramidite RNA Synthesis

33. Prepare a small glass column containing about $10 \mathrm{~cm}$ of silica gel packed in $98: 2$ dry methylene chloride:triethylamine. 


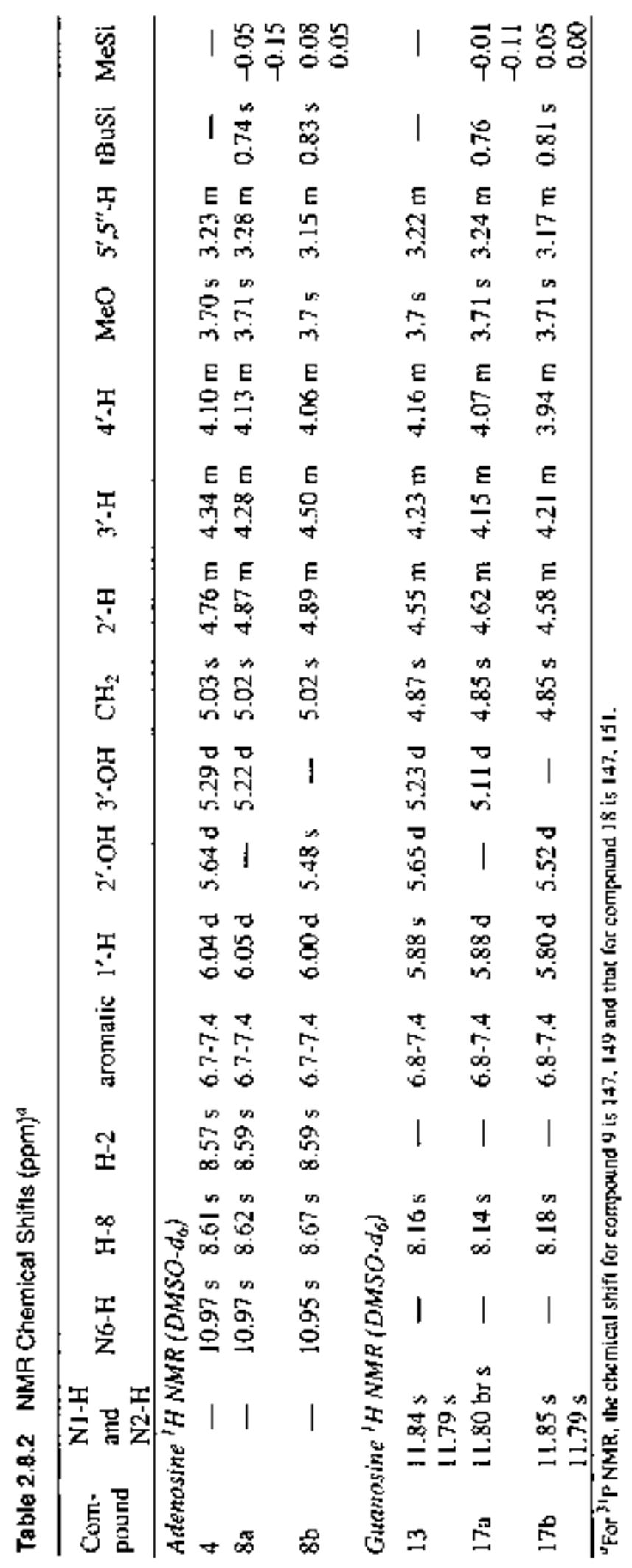

Protection of

Nucleosides for

Oligonucleotide Synthesis 
34. Place the reaction mixture directly onto this column and load it using nitrogen pressure. Wash the column using nitrogen pressure with about $30 \mathrm{~mL}$ of $98: 2$ dry methylene chloride:triethylamine, followed by 49:1:50 dry methylene chloride:triethylamine:dry acetonitrile.

The product normally elutes after 20 to $50 \mathrm{~mL}$, sometimes just after a yellow impurity.

It is very important to work as quickly as possible so as not to leave the product in solution any longer than necessary, since it will start to degrade immediately. A quick way to check the fractions for product is to spot them on a grid marked on a TLC plate. The plate does not have to be developed, just checked for UV-active material. Then the first and last fractions can be checked by HPLC or on a developed TLC plate.

36. Combine the fractions containing pure product and evaporate to a foam. Dry the product in a desiccator over $\mathrm{P}_{2} \mathrm{O}_{5}$.

37. Check the product for purity by ${ }^{31} \mathrm{P}$ NMR (Table 2.8.2).

\section{REAGENTS AND SOLUTIONS}

Use deionized, distilled water in all recipes and protocol steps. For common stock solutions, see APPENDIX 2A; for suppliers, see SUPPLIERS APPENDIX.

\section{Adenosine phenoxyacetylating reagent}

Co-evaporate $2.03 \mathrm{~g}$ ( $15 \mathrm{mmol})$ of 1-hydroxybenzotriazole and $2.2 \mathrm{~mL}(20 \mathrm{mmol})$ $\mathrm{N}$-methylmorpholine two times with $20-\mathrm{mL}$ portions of acetonitrile. Dissolve the residue in $50 \mathrm{~mL}$ dichloromethane. Add $2.1 \mathrm{~mL}(15 \mathrm{mmol})$ phenoxyacetyl chloride and shake for $10 \mathrm{~min}$. Prepare fresh.

\section{Ammonium phenyl-H-phosphonate}

Add $38.3 \mathrm{~mL}(0.20 \mathrm{~mol})$ diphenyl phosphite over $10 \mathrm{~min}$ to $400 \mathrm{~mL}$ of $7.4 \mathrm{M}$ aqueous ammonia. Stir for $1 \mathrm{hr}$. Concentrate to dryness and co-evaporate the residue two times with $100-\mathrm{mL}$ portions of absolute ethanol. Stir the residue with $400 \mathrm{~mL}$ ethyl ether for $30 \mathrm{~min}$ to give up to $85 \%$ of the colorless crystalline product. Store up to 1 month at $-20^{\circ} \mathrm{C}$.

\section{Diisopropylammonium tetrazolide}

Place $2.00 \mathrm{~g}(28.5 \mathrm{mmol})$ of solid tetrazole in a dry $250-\mathrm{mL}$ round-bottom flask containing a dry stir bar and add $130 \mathrm{~mL}$ of dry acetonitrile. Stir until dissolved, then add $9.0 \mathrm{~mL}$ ( $63.9 \mathrm{mmol})$ of freshly distilled diisopropylamine. After $2 \mathrm{~min}$ of stirring, collect the white precipitate by filtration in a dry glass funnel and wash it four times with $10-\mathrm{mL}$ portions of dry acetonitrile. Dry the solid in a desiccator over $\mathrm{P}_{2} \mathrm{O}_{5}$. Store up to 3 months at $-20^{\circ} \mathrm{C}$.

\section{Guanosine phenoxyacetylating reagent}

Co-evaporate $1.35 \mathrm{~g}$ (10 mmol) of 1-hydroxybenzotriazole and $1.1 \mathrm{~mL}(10 \mathrm{mmol})$ $\mathrm{N}$-methylmorpholine two times with 20 -mL portions of acetonitrile. Dissolve the residue in $25 \mathrm{~mL}$ dichloromethane. Add $1.39 \mathrm{~mL}(10 \mathrm{mmol})$ phenoxyacetyl chloride and shake for $10 \mathrm{~min}$. Prepare fresh.

\section{COMMENTARY}

Regioselective 2'-Silylation of Purine

Ribonucleosides for Phosphoramidite RNA Synthesis

\section{Background Information}

The procedures described here use adenosine and guanosine that are $5^{\prime}$-protected with the 4,4'-dimethoxytriyl (DMTr) group and amino-protected with the labile phenoxyacetyl group (Wu et al., 1988; Chaix et al., 1989; Singh and Nahar, 1995; Sinha et al., 1995). They should also be applicable to nucleosides containing most other amino-protecting groups. Amino protection of adenosine with the benzoyl group and guanosine with the isobutyryl group can be carried out by standard literature 
procedures, and these derivatives are more easily handled than are the more-labile phenoxyacetylated compounds. A general discussion of amino-protecting groups and literature references is given in UNIT 2.1.

The procedures developed by Ogilvie for 2 '-silylation proceed with only modest regioselectivity (Ogilvie, 1978, 1979). Although use of silver nitrate improves the selectivity, the results are variable and do not approach the selectivity of the above protocols (Hakimelahi, 1982). A general discussion of $2^{\prime}$-protecting groups, including the $2^{\prime}$-TBDMS group, is given in UNIT 2.2.

\section{Critical Parameters}

The most difficult of the above protocols to carry out are the tritylation and phenoxyacetylation steps used for preparation of $\mathbf{S . 4}$ and S.13. Skill and practice are required to achieve high yields on these protection reactions, largely because of the phenoxyacetyl group. In contrast, the regioselective silylation and dephosphonylation reactions work well even in the hands of unskilled researchers.

\section{Anticipated Results}

For the reasons discussed above, some experience is required to achieve high yields for the phenoxyacetylation reactions, and initial efforts are likely be give more modest yields (e.g., 50\%). With experience, yields of $\sim 90 \%$ can be expected. The regioselectivity of the silylation reaction is invariably $85 \%$ to $90 \%$ regardless of experience.

\section{Time Considerations}

The total time for conversion of adenosine or guanosine to the fully protected derivatives S.8a and S.17a, respectively, is $\sim 1$ week.

\section{Literature Cited}

Chaix, C., Duplaa, A.M., Molko, D., and Téoule, R. 1989. Solid phase synthesis of the $5^{\prime}$-half of the initiator t-RNA from B. subtilis. Nucl. Acids Res. 17:7381-7393.
Hakimelahi, G.H., Proba, Z.A., and Ogilvie, K.K. 1982. New catalysts and procedures for the dimethoxytritylation and selective silylation of ribonucleosides. Can. J. Chem. 60:1106-1113.

Ogilvie, K.K., Beaucage, S.L., Schifman, A.L., Theriault, N.Y., and Sadana, K.L. 1978. The synthesis of oligoribonucleotides. II. The use of silyl protecting groups in nucleoside and nucleotide chemistry. VII. Can. J. Chem. 56:27682780.

Ogilvie, K.K., Schifman, A.L., and Penney, C.L. 1979. The synthesis of oligoribonucleotides. III. The use of silyl protecting groups in nucleoside and nucleotide chemistry. VIII. Can. J. Chem. 57:2230-2238.

Singh, K.K. and Nahar, P. 1995. An improved method for the synthesis of $N$-phenoxyacetylribonucleosides. Synth. Commun. 25:1997-2003.

Sinha, N.D., Davis, P., Schultze, L.M., and Upadhya, K. 1995. A simple method for $N$-acylation of adenosine and cytidine nucleosides using carboxylic acids activated in situ with carbonyldiimidazole. Tetrahedron Lett. 36:9277-9280.

Song, Q., Wang, W., Fischer, A., Zhang, X., Gaffney, B.L., and Jones, R.A. 1999. High yield protection of purine ribonucleosides for phosphoramidite RNA synthesis. Tetrahedron Lett. 40:4153-4156.

Wu, T., Ogilvie, K.K., and Pon, R.T. 1988. N-Phenoxyacetylated guanosine and adenosine phosphoramidites in the solid phase synthesis of oligoribonucleotides: Synthesis of a ribozyme sequence. Tetrahedron Lett. 29:4249-4252.

Zemlicka, J. 1963. Reactions of dimethylformamide acetals with some heterocyclic systems. Collect. Czech. Chem. Commun. 28:1060-1062.

Zhang, X., Abad, J.-L., Huang, Q., Zeng, F., Gaffney, B.L., and Jones, R.A. 1997. High yield protection of purine ribonucleosides for $H$-phosphonate RNA synthesis. Tetrahedron Lett. 38:7135-7138.

Contributed by Barbara L. Gaffney and Roger A. Jones

Rutgers, The State University of New Jersey Piscataway, New Jersey
Protection of Nucleosides for Oligonucleotide Synthesis

2.8 .13

Supplement 6 